\title{
Word-recognition threshold as a function of pretest sensitization
}

\section{T. A. NOSANCHUK AND ROBERT D. HARE \\ UNIVERSITY OF BRITISH COLUMBIA}

The hypothesis that the administration of a questionnaire sensitizes a respondent to relevant issues and concepts was examined. Ss presented with information in the form of a questionnaire were found to have lower word-recognition thre sholds to related concepts than did $S$ s who had been presented with the same information in statement form, thus supporting the hypothesis.

The Pretest-Treatment-Posttest design, though common in the social sciences, has long been recognized as imperfect. What is often interpreted as change due to treatment may be due, at least in part, to the "sensitizing" effect of being pretested and to the interaction between pretest and treatment (Campbell, 1957; Solomon, 1949). For instance, the administration of a questionnaire may increase the awareness and responsiveness of a $\mathrm{S}$ to relevant issues and concepts. This "pretest sensitization" could then influence the effects that subsequent treatment conditions have upon him. However, efforts to assess the effects of pretesting have produced inconsistent results. For example, some investigators have found that pretest has a facilitating effect upon subsequent performance (Lana \& King, 1960), while others have found that such a pretest has either no effect (Entwisle, 1961) or that it produces a decrement in performance (Solomon, 1949). The conflicting results obtained in studies such as these may reflect differences in the procedures and Ss used, and also the frequent use of factorial designs in which one factor is pretest vs. no pretest and the other treatment vs. no treatment. In this design, the effects due to pretesting and those due to the pretest-treatment interaction may, theoretically, be isolated. However, as Ross \& Smith (1965) have pointed out, effect estimates cannot easily be made since uncontrolled events may intervene between the pretest, treatment, and posttest, thus involving an additional main effect as well as interactions in the analysis.

An alternative way of estimating the main effect of pretesting might involve using the pretest as the treatment, a control group for baseline evaluation, and indirect and immediate measurement of effects. Such a procedure would eliminate the influence of uncontrolled events and would provide an estimate of the effect due to pretesting. In the present study, Ss in the experimental group were questioned about their attitudes towards several current issues while Ss in the control group were simply required to read material on the same issues. Word-recognition thresholds for concepts embedded in these issues were then determined for both groups. The assumption was that the act of questioning Ss about an issue (pretesting) would lower their recognition threshold for related concepts.

\section{Method}

Two sets of items were put together. One set (E) consisted of a 10-item questionnaire dealing with topics of current interest and headed by these instructions: "We would like to get your opinion on a number of issues. There are 10 questions following-please read each question carefully and check that alternative which is closest to your own opinion. Answer all of the questions." An example of the items in this set is as follows: E.2 "The question of capital punishment is soon to be debated by parliament. What are your views on this issue? (a) Should be maintained, (b) Should be abolished except for killing of prison guards and policemen, (c) Should be abolished, (d) No opinion." The other set (C) consisted of similar items, but in the form of descriptive statements and headed by these instructions: "On the next few pages you will find 10 short paragraphs on topics of current interest in the United States and Canada. Please read each one carefully. Place a check mark by each paragraph as you finish it. Do not skip any paragraphs." An example of items in this set is as follows: C.2 "The issue of capital punishment is soon to be debated by parliament. M.P.'s have been freed from voting with their party on this issue. While any possibility of wrongful execution would be eliminated by the abolition of capital punishment, there are many who feel that a powerful deterrent to crime would also be removed." Thus, while both items dealt with the concept of capital punishment one was in questionnaire form and the other in statement form.

The two sets of items were randomly distributed to a class of undergraduate students. Twenty-one of the Ss received the $E$ set (experimental group) while 19 received the $\mathrm{C}$ test (control group). After all Ss had completed the set assigned to them, they were each handed a specially prepared pad consisting of eight sheets, each sheet containing the numbers 1-10 down the left margin. The room was then dimmed slightly, and the attention of the Ss drawn to a large projection screen situated on the front wall of the room. They were told that a series of words and phrases would be flashed on the screen and that they were to write down whatever they thought they saw, and to guess when in doubt. Ten concepts, each related to one of the 10 items contained in the $\mathrm{E}$ and $\mathrm{C}$ sets (e.g., Capital Punishment), were flashed upon the screen for $1 / 100$ 
sec. each (below threshold for all Ss), with the Ss being instructed to write down whatever they thought they saw. They then turned the page of their pad and the 10 concepts were presented again, but in a different order and at a slightly slower speed. The process was repeated eight times, with the final presentation time being $1 / 5$ sec., a value above recognition threshold for most of the Ss.

\section{Resulis and Discussion}

In three items, the concepts flashed upon the screen had been used with substantially different frequencies in the $E$ and $C$ sets and so were excluded from the analysis. Of the remaining seven concepts, three appeared once in both $\mathrm{E}$ and $\mathrm{C}$ sets, two occurred twice in the $\mathrm{E}$ and once in the $\mathrm{C}$ set, and two appeared once in the $\mathrm{E}$ and twice in the $\mathrm{C}$ set.

In computing an individual's score, only complete recognitions were considered. For each of the seven concepts, the median recognition threshold for all Ss was computed, and each S's score taken as the number of times his recognition threshold was at or below the median. The scores thus obtained could and did range from 0 to 7 . The mean score of Ss in the experimental group was 4.05 while $\mathrm{Ss}$ in the control group received a mean score of 2.79 , a difference that was statistically significant $(t=2.10$, df $=38, p<.025$, onetailed test). Thus, the hypothesis that a pretest questionnaire "sensitizes" an S to relevant concepts was supported.
A primary consequence of this study seems to be the provision of evidence permitting the imputation of a main effect due to pretesting. Because the measurement of effect is both indirect and immediate, uncontrolled events and interactions a re eliminated, isolating the pretest effect. However, this study, like nearly all previous studies in the area, used students as Ss. It can be argued that such Ss may respond to questions, particularly in the context of the classroom, in ways which are not representative of the rest of the population. Thus, the replication of this study on more representative groups seems indicated.

In order to obtain a better idea of the absolute magnitude of the sensitization, an additional control group, one receiving no treatment, could be added. This could consist of the presentation of equivalent information in either question or paragraph form, but without the key concepts imbedded.

\section{References}

Campbell, D. T. Factors relevant to the validity of experiments in social settings. Psychol. Bull., 1957, 54, 297-312.

Entwisle, D. R. Attensity; factors of specific set in school learning. Harv. Educ. Re v., 1961, 31, 84-101.

Lana, R. E., \& King, D. J. Learning factors as determiners of of pretest sensitization. J. appl. Psychol., 1960, 40, 189-191.

Ross, J. A., \& Smith, D. Experimental designs of the single stimulus, all-or-nothing type. Amer. Soc. Rev., 1965, 30, 68-80. Solomon, R. An extension of the control group design. Psychol. Bull., 1949, 46, 137-150. 